\title{
A Glimpse to the Differences between Chinese and American Family Education from the Film a Grandson from America
}

\author{
Chunxia Zhang \\ Foreign Languages School, Jingchu University of Technology, Jingmen, Hubei, 448000 \\ 568273258@qq.com
}

Keywords: Family education; Historical background; Cultural background; Enlightenment

\begin{abstract}
Education is a systematic project, including family education, school education and social education. Family education is very crucial. China and America occupy an important position in the world as great powerful countries. China is the largest developing country. America is a highly developed capitalist power. Therefore both of them are enough to be a typical representative of eastern and western education.
\end{abstract}

\section{Introduction}

Education is not only a social behavior to cultivate human, but also a major way of passing social culture and experience. "Education as a Necessity of Life." [1]Family education is the earliest and most important of all kinds of education method, and it plays an important role in the children's thinking mode and the formation of the world. Different society needs different family education. As Mei pointed out, family, as the basic unit of a society, is very much like a mirror, reflecting a society's cultural characteristics, moral beliefs, economic and political relations and other social problems.[2]As the old saying goes: "Parents are the best teachers." With the development of China's social and economic, the importance of family education in China is higher and higher. However, due to the lack of comprehensive theoretical support, there are some misunderstandings in the family education, which also become a barrier to good moral character training of the younger generation. Some Chinese parents have not been aware of the importance of family education, and regard the education as the teachers' job. Some families know the importance of education, but use a number of unreasonable methods in the practical educational process.

Understanding and learning valuable education in other countries better is not only to inspire parents to pay more attention to family education in China, but also to help them to find a better way to educate children. Due to different social conditions and historical reasons, the Chinese people cannot accept American education, but the opening world will keep education all over the world together so that each country can find and use the best mode family education which suites to their own situation.

\section{The Differences of Family Education}

The Differences of Family Education Concepts. In the film A Grandson from American, Brooks who is a child but has a very strong independence, when he pillows the bed then he does not seek the help of Grandpa, but taking responsibility and air his quilt by himself. When Brooks sees the spider on the tree, he firstly observes the spider alone. After Yang sees that he does not ask what Brooks is watching and he says: Maque, zaofeile. (This is sparrow's home, but the sparrow has gone.) This is the common way for most Chinese parents, they only do what they can but do not ask what they want. Then Brooks comes up with an idea that he uses ladder to help him. But he cannot carry it. At last, Brooks climbs the tree by himself. The different education concepts lead to different education for children both in China and America. In fact, education is a kind of social activity that can cultivate human. Chinese parents pay more attention to the promising future, a good job, and a good life. In the concept, Chinese family education emphasizes the relationship between the individual and the whole family, focusing on children through learning cultural knowledge and skills. Due to these expectations, most parents think that their responsibility is to 
offer better and better condition for their children. Even the children could do nothing except studying and getting good grades. "Just as Phierbaha says, "Parents' biggest false is they stand in their position and interfere children's nature development."[3] Chinese parents would like to offer everything no matter what they could sacrifice if their children can live with their help.

On contrary, American parents believe that the growth of their children is very close to their own strength and experiences. American parents pay more attention to the cultivation of children's independence and social adaptability. Due to this concept, most American parents pay attention to train their children's ability of self-supporting and independence since their children are very young."The contents of American family education are very plentiful. American parents pay attention to their children"s all-round study."[4]

The Differences of Family Education Aim. From the film, Because Aihua works in China, Brooks is sent to Chinese school to learn Chinese to integrate into environment better. During the time Brooks stays with Yang, Brooks can speak Chinese very well. But as we Chinese students, we also learn English, but most of us would pay more attention to the grades on the paper. As for the ability of speaking English, it would be paid less attention. It leads to high scores and low abilities.

The family education aim is to cultivate the children to grow up in some families' direction. It is the limiting factor for the direction of family education, deciding the common effect of it. So the family education aim is the key of family education and the fundamental reason for the differences between the two countries on family education.

There is an essential difference between two countries' aims of family education, with the expectation that the child could become excellent and hope the child to be a comprehensive and independent person.

To most Chinese parents, the aim is expecting their child to be a "dragon", which is "wang zi cheng long' in Chinese. But American parents take hoping the child to be an able man, which is "wang zi cheng ren" in Chinese as their aim. China's family education focuses on children's future relative determination of the examination and grades. For Chinese parents, their aim is to do anything to support their children to get high marks. What forms apparent contrast is American parents give their children more training about improving abilities. And America's family education emphasizes more on children's creative power survival and social practice education. They try to train their children to have the ability of adapting to environmental variety and the ability of living independently.

The Differences of Family Education Methods. Regardless of the differences between China and America in family values, love between family members is still the eternal theme. Therefore, when Yang educates Brooks, what he says more is asking him to be obedient, rather than reciprocal exchanges and communication with him. At first, when Yang knows Brooks is left for him to take care. Yang says: You must stay here honestly. I am going after your mother to ask her back. Understand? And then Yang roars at Brooks, and says loudly: Do you understand? At last, Yang locks Brooks in his house. As we know, home is the safest place for children. But in America, leaving children alone at home is an illegal conduct. When Brooks sees Old Yang flipping his bag, he immediately says: Stop! That is mine! At first, Yang is very surprised. During his lifetime, he has not known what is privacy. But from the view of Brooks, he thinks that he was not respected. Because American parents respect children's privacy, and American parents have no right to check personal goods without permission. Generally, in American families, "parents mainly use an equal way to educate their children. They respect children's personality and rights. Children, in the family, are treated as independent individuals."[5] When it is time for dinner, he explicitly requested, "I want to eat a hamburger." This illustrates that the Americans had been taught to come to their own requirements, ideas, and concept of individualism. Chinese people who are in the same situation, often use more indirect way. Especially when Brooks makes a phone call to Brooks' mother, cultural stations owner teaches Brooks how to communicate with the mother word by word, but Brooks got the phone into one side, and talk to his mother independently. In real life, the Chinese will teach your child about every word and every detail, rarely give time and space for children to play. However, the Americans have focused on cultivating children's independent spirit, requiring 
children to have a strong capacity for independent living. When Yang knows Brooks pillows the bed, Yang says, "How old are you? Are you not ashamed?" to Brooks to hurt Brooks' self-esteem. After these words, Brooks goes to the house and takes his schoolbag with him and plans to run away from home. What Yang says is our common ways that teacher and parents use to shame the children. For Chinese parents now, there are some children who are not their own children but others' and in high grades called "other people's children". Chinese parents always use "other people's children" to shame their own children.

The method of family education is the specific measures that parents use to complete the education, which is related with the complement of education purpose and education content. The method of education in China is decided by parents. In Chinese family, affected by Chinese traditional culture, parents educate children by "control" and "seal" type. There are three types:

(1) Chinese parents prepare everything for their children in daily life. In Chinese family, there is little need for children to do housework.

(2) Chinese parents protect the children to excess in social activities. Many children are prevented from exposure to the outer world because their parents worry about children's being affected by bad things.

(3) Chinese parents have a strict attitude toward children's study. Parents regard the grades as the only standard for future success. "Tasks Sea" strategy is often used in study. Chinese children are tired of doing the extra exercises.

The differences of family education between the two countries are also reflected in the family education methods. Although the contents of Chinese family education can also be divided into moral education, intellectual education, physical education and artistic education, but intellectual has been the most important one since they go to school. However, the contents of American family education are abundant, which pay more attention to the harmonious development of language, emotion, knowledge and so on. It is so-called "education for all-around development.

Chinese believe that there is an inextricable relationship between family members, but because of seniority, the child must listen to the advice of their elders just like the children are their accessory. The children also do not have any privacy. Parents control children's nearly all kinds of things even once they found that their children have some unusual trends. Parents do not make conversation with children, but guess and search children's phone calls and letters secretly。At the same time, children are one part of the family, who is in need of care and concern. Americans believe that family members should be equal; everyone at home should be independent, free and equal individuals. Family education focuses on fostering children's independence, requiring children to share housework to cultivate the ability of independence.

\section{Factors Contributing to Difference in Family Education between China and America}

Family education refers to educational influence that parents had on the growth and development of their children in the process of family interaction, which has played a vital role in the education of the whole society. Family, the first belonging group when man was born, is a place where the basic personality of human being came into being, therefore, family education is of great significance on man's future development. Parents are the enlightening teachers of their child, thus their words and behaviors exert a profound influence on the growth of their child. Therefore, family education is the beginning of the whole education process, and has a far-reaching significance on children's habits, interest, lifestyle, and even the cultivation of personality. The key of family education lies in in the fact that its influence on the kid is subconscious and involuntary. Simply, kids unconsciously accept the common sense of life and cultural value by observing and imitating. So, we dare say that different family educations are bound to generate ways of speaking, ways of thinking and ways of doing between Chinese and Western.

Reasons of Different Historical Backgrounds. America is a country of immigrants with short history, where outdated ideas are rarely preserved; under the influence of the diverse culture values, new ideas and cultures are more likely to be accepted and developed without being confined. Thus, 
comparatively speaking, Americans are more adventurous and innovative. According to Hofstede, there are less authoritarian relationship between parents and children, which means that they are equal most of the time.[6]

While China is a nation with a long history and culture, at the same time, suffered from more restraints, partly due to the long-been influenced by small-scale of feudal peasant economy, cultural values in China tend to be more conservative, thus, greatly lack of adventurous and creative spirits, and Chinese people are infused with submissive and obedient thoughts when they were children. Comparatively speaking, Chinese education lacks the environment to absorb new ideas.

Chinese cultural tradition is a kind of ethnic cultures. Chinese culture-orientation is to pursue the perfection of personality. Therefore, family education attaches great importance to fostering "etiquette", cultivating the sense of community and collectivism. In terms of the relationship between individual and collectivity, it stresses subjecting to collectivity unconditionally, individual is at the service to collectivity, thus objects to sense of independent and moving to a path that is totally different from the original. Chinese ethnic norms: "ruler guides subjects, father guides son" become a dominant role in the process of family education. It is a common advocacy that parents discipline their children to be meek and submissive and the words said by parents are above anything. There is no doubt that such a controlled family education whose evaluation from its subject, criteria and process, as a result, is merely decided and made by parents, while their children cannot involve in its evaluation. They have no chance to express it even they have their own ideas. Therefore, Chinese children, to some extent, tend to be conservative, introvert, dependent; while American children are more aggressive, extrovert, independent. Chinese parents often use horizontal comparison to gradually guide children to measure themselves through external criteria, by doing so, letting kids understand and adjust their position in groups. As a result, the kids that they fostered and shaped tend to be the same, and lack of individuality.

The principal part of American cultural tradition is individualism. In American cultural tradition, individualism emphasizes personal independence and creativity, stresses individual's free development and responsible for yourself, and not confined or less confined by social, political and religious forces. The key to individualism is the principle of mutual-benefit and voluntary, which sees collectivity as the collective of individual and the resources of personal development. American culture underlines people-oriented, the purpose of education is to promote individual potentials and the development of creativity. Collectivity should satisfy and respect the legitimate needs of individual. Family education is for the sake of child's future development, and provides them with an optimistic, active, creative and confident environment. Therefore, American parents attach great importance to cultivating child's awareness of independence and free development, encouraging them to try all kinds of new things, and enhancing self-cultivation by practice.

Reasons of Different Social Conditions. In film, Yang uses Young Pioneer to praise that Brooks is brave and does not cry when Brooks is spilled from the tree and get hurt. But Brooks cannot understand the meaning of Young Pioneer. But in America, there is no concept of Young Pioneer. Because America is not socialist country, there is no Young Pioneer in America. China is a country directly derived from a feudal society to a socialist one, thus there still exist some feudal thoughts which have exerted impact on social life. For example, the evaluation mechanism of the current exam-oriented education, to a certain degree, is very similar to imperial examination system in ancient China. After new China was founded, our country's education is influenced by planned economy system and higher education modes of the Soviet Union. Therefore, management system on education adopts highly centralized mechanism. Since the implement of reform and opening policy, such situation has somewhat been improved, but in fact, colleges and universities still have limited power of themselves.

In America, where they have experienced a series of great historical event such as renaissance and glorious revolution, industrial revolution, many countries step on the road of capitalism. Thus, people emphasize the importance of pursuing freedom, democracy, human rights, and technology. Under the influence of such Western education notion-----Americans stress the cultivation of individuality, and encourage innovative invention. At the same time, American education was 
founded on market economic system, colleges and universities have more freedom to develop on their own needs.

Reasons of Different Family Education Concepts. Education concept, in short, is people's fundamental view or attitude to education. While the crucial part of education concept is the education value, that is people's opinion concerning the significance of education on human beings and society. Due to many complicate historical and realistic reasons, many widely different education concepts gradually came into being in the long process of social and educational progress in China and Western countries, and thus there appear different characteristics of theory and practice.

American Education Concept. American culture emphasizes pure knowledge, thus Americans only acquire knowledge, especially scientific and social knowledge. Their parents argue that knowledge originates from curiosity, therefore they often take their children back to nature so as to arouse child's interest of nature and science. American education is centered on students, and stresses individual's efforts and equality. Parents fully respect kid's individuality and self-esteem, encourages them to think independently, and gives them freedom. Parents are strongly convinced that kids should grow up naturally in accordance with their interests and individuality rather than follow other's wills, so they seldom force their children. Parents' responsibility merely lies in exploiting child's interests and potentials, and guides them on the right track. They are fully aware that real education should not be coercive; interests cannot come out of force; enforcement only leads to destroying kid's ingenuity and interest. For them, kid's heart, is not a can that needs to be filled, but a tinder that needs to be lighted. "Because western civilizations emphasize struggle, equality, democracy and human nature, western family usually pays great attention to the individuality and comprehensive quality.'”[7]

Chinese Education Concept. Compared with American education concept, Chinese education concept is quite different. Confucianism is deep-rooted in Chinese mind, its core notion are "life", "morality", "ethic". Therefore, Chinese parents attach great importance to Confucianism of Confucius and Mencius, Chinese people acquire "gentleman's doctrines" when they enter school. Chinese traditional cultures emphasize collectivism and harmony, and confine individuality. Confucius's "benevolence" represents the essence of Chinese culture, "etiquette" is the most important part of education. Influenced by such thoughts, many Chinese parents enlighten their children to be good children, but there is a strong sense of "authority" within Chinese family. The most fundamental principles of Patriarchy in Chinese tradition are "father guides son". Parents, especially father's dictations or orders, his children must obey unconditionally. Children should be awesome to their father, and keep certain distance to set up a sense of "authority". Parents underline unilateral factor of their child's growth, neglect the development of individuality. Parents do not consider their children as independent individuality, instead, and treat them as personal property. In such families, children are deprived of initiative and creativity, blindly follow their parents instructions, they dare not challenge so-called "authority" at all. Therefore, "good kids" are evaluated by self- restraint, obedient, politeness, and modesty and the likes, which are accordance with the advocacy of Confucianism. Besides, Chinese parents pay more attention to knowledge that their children do not acquire, while American parents merely care about knowledge that their kids had grasped. In addition, Chinese parents emphasize the limitations of their children, but American parents stress the new accomplishments of their kids. Moreover, Chinese parents seldom satisfied with their children, and always place a higher demand on them, while American parents basically centered on encouragement.

\section{The Enlightenment between American Family Education and Chinese Family Education}

Updating Family Educational Concept. "Family education plays a fundamental role in the growth of individual, and in the formation and development of general mood and culture of society." [8] Sow a thought, reap an action. Improving the quality of Chinese family Education must be under the guide of updating family education concept. Because of reactions on an equal footing 
between parents and children in America, American parents would not punish their children do what their children are unwilling to do. The result of American education is that American children will be more tractable. On the contrary, what Chinese parents do mostly is to punish their children do no matter what their children are willing or unwilling to do. The result of Chinese parents is that the children in China less tractable but more reasonable. So, the first action of change people's behavior is to change the people's concept. There is nothing wrong for parents caring for their children and children who are in care will grow up healthy, but parents should let their child take practice in life skills to try the test of success or failure. Secondly, transform authoritarian education and establish a democratic education. Chinese parents should also consider their children to be with their own people of equal status, respect them and treat them on an equal footing like American parents, give them more freedom to choose right, give children more independent choices and respect the choices that children make. Thirdly, change the enclosed view of education and set up the open learning education concept. Knowledge is undoubtedly very important for children, but the problem is that China's teachers, parents and children the learning space of China's teachers, parents and children are almost always limited to knowledge of the world as a whole. "The main aim of education is to teach children to learn from how to live to care other people then responsible for others." [9] Therefore, family education should be to liberate children from books, home and school, we should let them participate in the necessary activities out of the classroom, out of school, and out of the family into the wider space. Finally, change group education and set up the character education. There are not the same leaves in the world, so there are no two identical children. Parents should not compare their own children with others.

More Attention on Children's Development in all-around Way. American parents are more concerned with children's development in all-around way. Comparing American parents with Chinese parents, Chinese parents always encourage the children to develop in an all-around way only in word but not in their actual life. The reform of family education in China for the future could not depend on the words or thought but on action. Taking appropriate action is the key for children's development on an all-around way. Science education should be based on intelligence as the center of education, mix a child's physical, psychological, ideological character, the scientific and cultural quality, comprehensive, and integrated education together. In addition, the children's education should not just teach culture. Teaching them some cultural knowledge is necessary, however, the increase in knowledge will not necessarily bring intellectual development. Intelligence is the access to knowledge and use of knowledge and the wisdom, including observation, memory, thinking, imagination, skills and other factors. These intelligence factors are restraint and interconnected with each other, and often play a role as a condition of unity. Therefore, scientific intelligence education should be comprehensive, integrated, and all-around the intelligence factor education.

Cultivating Children's Ability of Thinking by Themselves. American parents are also concerned with children's ability of thinking by themselves. When the children make mistakes, American parents deal with it by encouraging the children to try their best to find the solution to resolve it. But Chinese parents will criticize the children for doing something wrong or tell the children the right way to deal with it. The way dealt with mistake by American Parents is worth learning for Chinese. It will form dependency for children when parents always find the solution for them. It will result that the children is lack of confidence and courage to face difficulties when the parents always pave the way to help children do with anything. Parents should understand children of psychological development features, and understand children of mood downs, and learning situation and life status, then try to attempts to view around world with children's perspective and thinking way to thinking problem. After the full understanding of children, parents should help children established self-respect and develop their potential in a more suitable way. Each children hopes to be respected and recognized, parents should treat children equally, respect their choice, and discuss with them friendly. And then let children do what they can do, such as cleaning the house, and stacking the quilt, and washing the bowl to practice their capacity. 


\section{Conclusion}

"As for education, there are three indispensable parts of it, namely, family education, school education and social education."[10] The role of family education is always present.When realizing importance of family education, and many problems of family education evaluation, more and more Chinese parents begin to feel that the traditional concept of family education is being challenged.At the time of facing with the children, parents cannot appear as an educator with condescending attitude. Child is an independent personality with his own individual and worldview. As for their own actions and thoughts, they have their own views. Parents should listen carefully to the child, and then join idea together with the child to avoid to causing family dictatorship. The process also can teach the children how to judge right and wrong and cultivate the ability of independent.

Secondly, parents should learn to be genuine respect for children, and create a family atmosphere of equality, democracy and freedom. To individual children's development prospects, parents should be careful about children's idea, because the children's response to the ideas influences the child's next action. The occurrence of inappropriate responses can lead to bad behavior and even crime. When parents are responding to children, parents are not suitable to displaying parental authority and parents should not compare their own children with others' children. In order to get rid of the previous response of a parental unilateral praise and criticism, American family members are so widely used that children can have a proper and objective evaluation. As for Chinese parents, the way they use criticism more than praise hurts children's self-respect badly. So making recommendations and plans for the future, it would be more beneficial to the child's development.

Finally, the family education is also an art. Parents should develop education plans according to the stage of children's physical and psychological development characteristics and personality traits. For different children, parents will use a different method that is suitable for other children may not be suitable for their children, instead of superstition from the experience of others. This requires parents to play wisdom to find a workable method when staying with children. Meanwhile, as the process of growing up, the child's self-consciousness and the ways of thinking are changing, so parents' plan should make adjustments based on the children' growth in time so as to ensure positive effects of education.

Based on the comparison of family education between China and America, there are some problems of the family education in China through analysis. Chinese purpose in family education and education backgrounds are very different. Thus the results in family education exert great differences. Take great advantage of useful educational experience abroad for reference, avoid the disadvantages, and combine with the actual situation of China family education programs which are suited to Chinese conditions in order to nurture talents for the development of China and provide good education.

Certainly, Chinese education also has advantages. As for the purpose of this paper, it is to attempt to find the disadvantages of Chinese education, the improper education concepts, purpose and method, and then make combination of the advantages both of Chinese and American. In this combination of conditions, it will provide better education both for parents and children in China.

\section{Acknowledgements}

This work is financially supported by Hubei Education Science "12th Five-Year Planning" (Project No.2014 A039) and Teaching Research Project of Jingchu University of Technology (No.JX-201634).

\section{References}

[1] Qing Yuan: DEWEY and Chinese (Chinese People's Publishing House, China 2001).

[2] Yiren Mei: American Studies Reader (Foreign Language Teaching and Research Press, China 2003).

[3] X.J. Guan: Social Sciences Journal of Colleges of Shanxi, Vol.17 (2005) No. 7, p.23-25. (In 


\section{Chinese)}

[4] Z.Y. L: Forum on Contemporary Education, Vol.062 (2007) No. 6, p:138-139.(In Chinese)

[5] Ying Li: Educational Practice and Research, (2005) No. 4, p.11-13.(In Chinese)

[6] Hofstede,G: Cultures and Organization: Software of the Mind: Intercultural Cooperation and Its Importance for Survival(McGraw-Hill,America 2010).

[7] W. L. Yan: School English, (2015) No. 10, p: 128-129. (In Chinese)

[8] B. Zhai: Educational Research,Vol. 434 (2016)No. 03,p. 92-98.(In Chinese)

[9] Q. R. Sun: Teaching, (2002) No.7, p.181-191. (In Chinese)

[10] http://www.cnki.net/kcms/detail/34.1209.G4.20161221.1115.164.html 